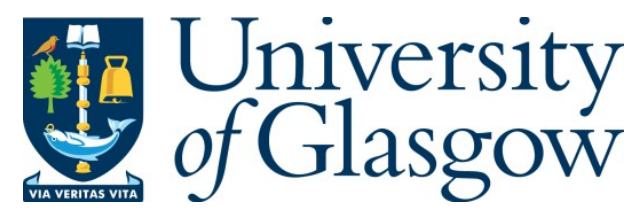

Dixit, T., Nithiarasu, P. and Kumar, S. (2021) Numerical evaluation of additively manufactured lattice architectures for heat sink applications. International Journal of Thermal Sciences, 159, 106607.

(doi: 10.1016/j.ijthermalsci.2020.106607)

This is the Author Accepted Manuscript.

There may be differences between this version and the published version. You are advised to consult the publisher's version if you wish to cite from it.

$\underline{\text { https://eprints.gla.ac.uk/225970/ }}$

Deposited on: 5 November 2020

Enlighten - Research publications by members of the University of Glasgow http://eprints.gla.ac.uk 


\title{
Numerical evaluation of additively manufactured lattice architectures for heat sink
} applications

\author{
Tisha Dixit ${ }^{\mathrm{a}}$, Perumal Nithiarasu ${ }^{\mathrm{b}}$ and S. Kumar ${ }^{\mathrm{a}, \mathrm{c}, *}$ \\ aDepartment of Mechanical Engineering, Khalifa University, Masdar Campus, Abu Dhabi, United \\ Arab Emirates \\ bZienkiewicz Centre for Computational Engineering, College of Engineering, Swansea University, \\ Swansea, United Kingdom \\ cJames Watt School of Engineering, University of Glasgow, Glasgow, G12 8LT, UK \\ *Corresponding Author (E-mail: s.kumar@eng.oxon.org; Phone: +44 141330 5529)
}

\begin{abstract}
Tailoring the architectural characteristics of lattice materials at different length scales, from nano to macro, has become tenable with emerging advances in additive manufacturing. Cumulative needs of high heat dissipation rates and structural requirements along with lightweight constraints have led to the development of several heat sink fins with lattice architectures in heat exchange-applications. Here, we numerically investigate the potential of polymer-based 3D printed lattice architectures as extended heat transfer surfaces and examine the forcedconvection characteristics of simple-cubic, body-centered-cubic and face-centered-cubic trusses as well as simple-cubic plate, and Kelvin and Octet periodic lattices with mesostructured architecture. All these lattices have a porosity of $77 \%$ (relative density $\sim 23 \%$ ) and surface area density in the range of $1500-2400 \mathrm{~m}^{2} / \mathrm{m}^{3}$. Thermal and hydraulic finite element studies were conducted for fluid flow over the lattice architectures for low Reynolds number in the range of $50-360$ and constant wall temperature conditions. The performance of different celltopologies is characterized in terms of exit fluid temperature, heat transfer coefficient with respect to different reference surface areas, pressure drop per unit length, Colburn factor $j$, Fanning friction factor $f$ and area goodness factor $j / f$. The study of the influence of thermal conductivity on heat transfer rate reveals that the polymer-based architected heat sinks perform close to their metallic counterparts when evaluated on per unit mass basis. Furthermore, bodycentered-cubic truss, simple-cubic plate, and Kelvin and Octet lattice-cells were found to exhibit better thermal performance than some microchannel and open-cell foam heat sinks.
\end{abstract}

Keywords: Architected materials; lattice materials; 3D printing; heat transfer; thermal management; heat sinks 


\section{Introduction}

The functional and/or mechanical performance of a lattice structure is dictated by its architectural design and material choice. There can be a multitude of permutations and combinations of various innovative design configurations and abundantly available choices of naturally-occurring or man-made materials. Nonetheless, the optimal choice is confined by the desired performance of the end-product. Additionally, the feasibility of fabricating the envisioned design is an equally important consideration. Many a times, a design is categorized as unrealistic owing to manufacturing limitations associated with the traditional manufacturing techniques. Additive manufacturing (AM), also known as 3D printing, has emerged as an indispensable technique enabling fabrication of complex architected 3D designs across multiple length scales (i.e. nano- to macro-scale) [1-3]. Some of the mainstream AM methods used for processing different classes of materials are fused filament fabrication (FFF), selective laser sintering (SLS), selective laser melting (SLM), stereolithography (SLA) and multijet fusion (MJF) [4]. Exponentially increasing popularity of AM is evident from the amply available table-top and low-cost varieties of 3D printers in the market. The foremost attributive feature of imparting the 'freedom of design' seems to have triggered instantaneous printing of 3D geometries previously confined only to two-dimensional drawings. Emerging advances in 3D printing has enabled realization of micro- and nano-architected 3D lattice materials, referred to as metamaterials $[5,6]$. Ultralightweight metamaterials [7], are commercially now produced [8]. A diverse number of lattice-cell architectures have been explored $[9,10]$. The most commonly employed architectures are octahedral [11], pyramidal [12], cubic truss/plate [13,14], Octet [15-17], Kelvin [16] and gyroid [18] lattices. These material architectures can be utilized for a multitude of applications such as for load bearing [19] and energy absorbing structures [17,20], thermal devices [20-22], battery electrodes [23] and medical devices [10,19,20,24].

For thermal management of heat exchange devices such as heat sinks and heat exchangers, stochastic as well as periodic cellular material architectures have been utilized [25]. These architectures impart high solid-fluid contact surface area, high surface area-to-volume ratio and low relative density while retaining the thermal characteristics of the basis material [26]. Nevertheless, the heat transfer rates of the periodic lattice architectures are found to be 
relatively higher than those of the stochastic foams owing to channelized straight passages [20]. This also results in lower fluid tortuosity leading to comparatively lower pressure drops. Moreover, introduction of tailored topology of ligaments and pores gives designer the freedom to concurrently optimize performance metrics such as weight, heat transfer rate and pumping power [27]. AM enables customization and/or fabrication of complex lattice-cell topology, with no additional cost. Recently, Jafari and Wits [28] have comprehensively reviewed heat transfer devices fabricated using SLS technique. The greatest advantage imparted by 3D printing in case of complex-structured heat sinks and heat exchangers is the complete elimination of contact resistance between base plate and fins as they are produced in a single build. However, they require joining in traditional manufacturing techniques, significantly contributing to contact resistance. Additionally, the process-induced surface roughness of AM-enabled materials can be beneficial in terms of enhanced fluid mixing and thereby enables higher heat transfer rates $[4,29,30]$.

Optimal design of heat sinks employing architected lattices warrants accurate evaluation of their heat transfer and pressure drop characteristics. Several researchers have undertaken such study for lattices such as tetrahedral [31], X-type [32], body-centered cubic [33,34], facecentered cubic [33], Schwartz [33], Kelvin [35,36], Octet [37] and Rhombi-Octet [29] under various heat transfer and fluid flow conditions. Wong et al. [38] experimentally evaluated the performance of 3D printed lattice architected aluminum heat sinks along with that of traditional pin-fin and rectangular-fin heat sinks. These lattice structures, despite having the highest surface area density, were found to exhibit relatively lower heat transfer rate. This could perhaps be attributed to its poor structural inter-connections and higher base plate-to-fin thermal resistance. On the contrary, Krishnan et al. [33] revealed a superior thermal performance of AMenabled lattice-structured investment cast copper heat sinks compared to parallel-plate heat sinks via a numerical study. Nevertheless, this observation was recently affirmed by measurements obtained on SLM-fabricated Rhombi-Octet aluminum lattices [29], which exhibit higher Colburn $j$-factor than the compressed random foams.

Although, high conductivity metals are an obvious choice, weight considerations necessitate the use of lightweight materials such as polymer composites [22,39-41]. Polymers and their 
composites are known for their low thermal conductivity and it therefore becomes challenging to achieve high heat transfer rates with polymer composites [42]. However, such limitation could be addressed by reducing the characteristic length scale of the heat sink to micro- and/or nanoscale and architecting its geometry in an ordered hierarchy. It is, therefore, vital to understand how the microarchitecture of different lattice-cell topologies affects the heat sink performance. Furthermore, in certain heat sink applications, demands of high cooling rates must be satisfied even at the cost of higher pumping power. In contrast, other applications may require a concurrent optimization of heat transfer and pressure drop characteristics. Therefore, based on the thermal and hydraulic characteristics, the categorization of different cell-topologies will facilitate a user-based choice of lattice structure depending on the multifunctional performance characteristics of interest.

This article presents a comparative assessment of the thermo-hydraulic performance of different mesostructured lattice architectures having surface area density in the range of $1500-$ $2400 \mathrm{~m}^{2} / \mathrm{m}^{3}$. Prototypes of these lattices as heat sink fins were fabricated by material jetting AM. The convective heat transfer and pressure drop characteristics were numerically evaluated at low Reynolds number and constant temperature base plate conditions. Effect of porosity (or relative density) of lattice architectures and properties of constituent material was also assessed. Our study reveals that the polymer-based architected heat sinks provide heat transfer rates similar to those of metallic counterparts when evaluated on per unit mass basis. Furthermore, some of the lattice-cell architectures were found to exhibit better thermal performance than that of microchannel and open-cell foam heat sinks.

\section{Lattice-cell Architectures}

In view of capitalizing high surface area-to-volume ratio, the lattice cell-topologies investigated in this study include cubic, Kelvin and Octet architectures. Elementary simple-cubic (SC) truss lattice is combined with body-centered-cubic (BCC) as well as face-centered-cubic (FCC) truss lattices so as to have high solid-fluid interactive surface area. This has also motivated the choice of simple-cubic plate-type lattice but with circular holes to permit fluid flow. Each unit cell has an overall dimension of $3.5 \mathrm{~mm} \times 3.5 \mathrm{~mm} \times 3.5 \mathrm{~mm}$ while that of the ligament diameter 
/thickness depends on the porosity (77\% considered here, conversely, relative density $\bar{\rho}=$ $23 \%$ ). A MATLAB code is written to accurately design the geometrical features based on the desired unit-cell size and porosity. The physical characteristics of the aforementioned mesostructured lattice architectures for $\bar{\rho}=23 \%$ are summarized in Table 1. It can be observed that the surface area density is the highest for SC-FCC-truss lattice and least for Kelvin lattice. In terms of the contact surface area between the lattice and base plate, SC-FCC-truss again surpasses all other geometries with SC-plate having the lowest value.

Table 1: Physical characteristics of different lattice-cell geometries

\begin{tabular}{cccccccc}
\hline $\begin{array}{c}\text { Sr. } \\
\text { No. }\end{array}$ & $\begin{array}{c}\text { Lattice } \\
\text { structure }\end{array}$ & $\begin{array}{c}\text { Unit } \\
\text { cell } \\
\text { length } \\
\boldsymbol{l}\end{array}$ & $\begin{array}{c}\text { Strut } \\
\text { diameter } \\
\boldsymbol{d}_{\boldsymbol{s}}(\boldsymbol{m m})\end{array}$ & $\begin{array}{c}\text { Relative } \\
\text { density } \overline{\boldsymbol{\rho}}) \\
(\%)\end{array}$ & $\begin{array}{c}\text { Surface } \\
\text { area } \\
\text { density } \boldsymbol{\beta} \\
\left(\mathbf{m}^{\mathbf{2}} / \mathbf{m}^{\mathbf{3}}\right)\end{array}$ & $\begin{array}{c}\text { Lattice } \\
\text { surface } \\
\text { area } \boldsymbol{A}_{\boldsymbol{s}} \\
\left(\mathbf{m m}^{\mathbf{2}}\right)\end{array}$ & $\begin{array}{c}\text { Contact } \\
\text { surface } \\
\text { area } \boldsymbol{A}_{\boldsymbol{c}} \\
\left(\mathbf{m m}^{\mathbf{2}}\right)\end{array}$ \\
\hline 1. & SC-truss & 3.5 & 1.23 & 22.959 & 1640.1 & 70.318 & 7.0971 \\
\hline 2. & SC-BCC-truss & 3.5 & 0.677 & 22.914 & 1773.8 & 76.053 & 4.3207 \\
\hline 3. & SC-FCC-truss & 3.5 & 0.637 & 22.996 & 2403.6 & 103.05 & 8.4 \\
\hline 4. & Kelvin & 3.5 & 0.745 & 22.917 & 1583 & 67.872 & 3.9137 \\
\hline 5. & Octet & 3.5 & 0.518 & 22.931 & 2171.7 & 93.113 & 4.5913 \\
\hline 6. & SC-plate & 3.5 & $\begin{array}{c}t=0.35 \\
d_{c t}=0.70\end{array}$ & 23.34 & 1714.1 & 73.491 & 2.3275 \\
\hline
\end{tabular}

Owing to the complexity of these architectures, prototypes of aforementioned six cell-topologies were additively manufactured using Objet260 Connex Polyjet 3D printer (Stratasys Ltd., USA). Lightweight polymer such as polypropylene is the preferred material choice; however, to realize micro- and meso-scale lattices accurately, UV curable resin, namely, VeroWhitePlus ${ }^{\mathrm{TM}}{ }^{\mathrm{M}}$ which can be processed by Connex family polyjet 3D printer was utilized. In order to demonstrate the feasibility of fabrication, VeroWhitePlus ${ }^{\mathrm{TM}}$ serves the purpose. 3D CAD files of the lattice-cells, generated using SolidWorks 2017 in stl format are given as an input to the printer. An array of $4 \times 4$ cells were 3D printed for each of the architectures being studied. Optical images of different 3D printed lattice architectures are shown in Fig. 1.

To ensure that the actual porosity of the 3D printed lattices is in accordance with the designed porosity, we measured the relative density of the 3D printed structures. Measurements showed 
almost the same level of designed porosity with negligible mismatch. With the SLA techniques such as the material jetting used in this study, geometrical features at micron-scale resolution can be easily realized. The resolution of the Objet260 Connex Polyjet multi-material 3D printer is $16 \mu \mathrm{m}$ in the $z$ - direction (thickness) and $42 \mu \mathrm{m}$ in the $\mathrm{x}$ - and $\mathrm{y}$-directions $[43,44]$. Therefore, the smallest geometric feature of the structures was designed to be at least an order of magnitude greater in size than the resolution of the 3D printer.

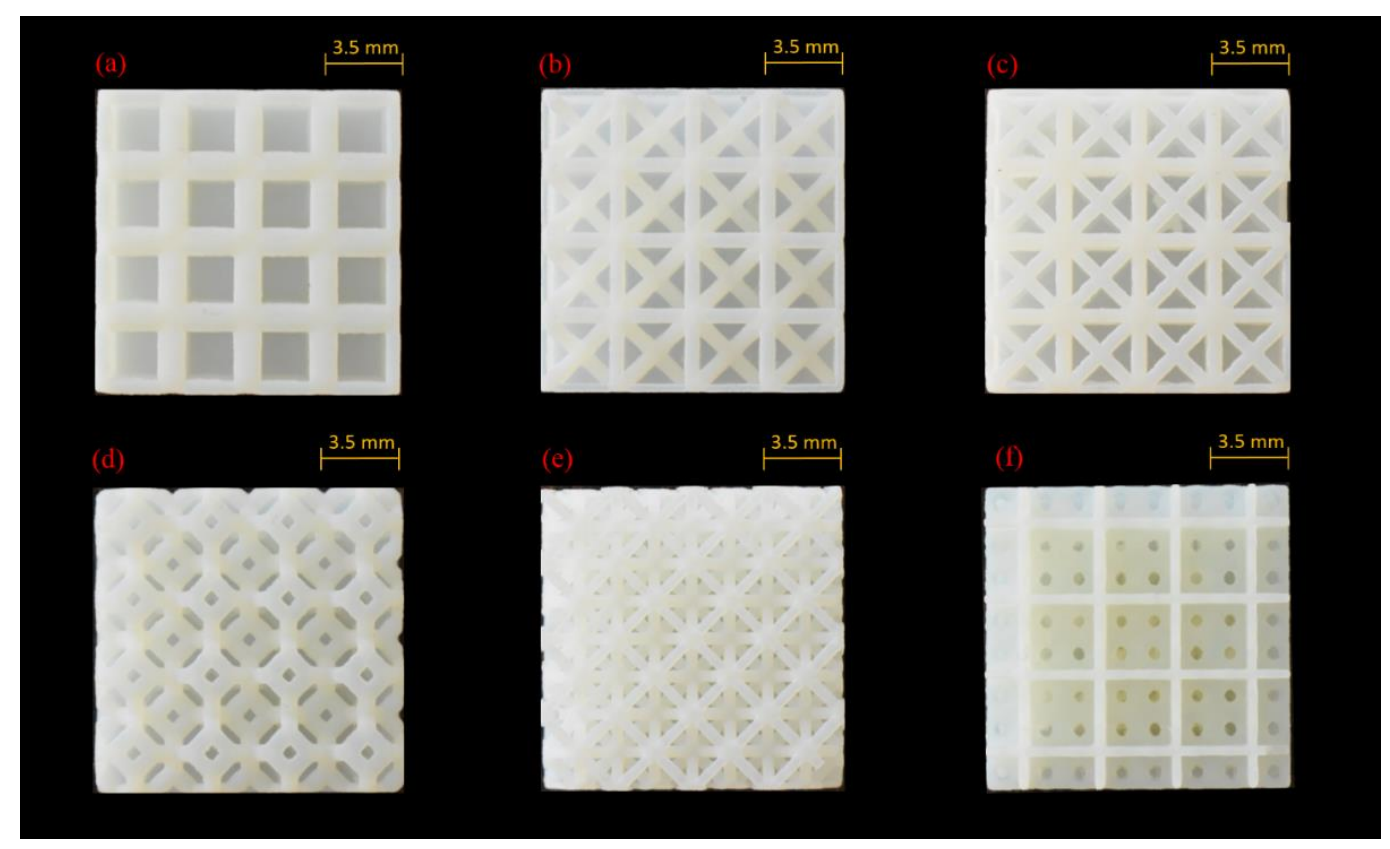

Figure 1: Optical images of the 3D printed heat sinks having $4 \times 4$ array of (a) SC-truss (b) SCBCC-truss (c) SC-FCC-truss (d) Kelvin (e) Octet (f) SC-plate lattices for 77\% porosity

\section{Computational Model}

The convective heat transfer and pressure drop studies of the lattice-cell architectures as extended heat transfer surfaces in heat sinks were conducted using the finite element tool COMSOL Multiphysics 5.3. The module 'Conjugate Heat Transfer, Laminar Flow' which combines the 'Heat Transfer in Solids' and 'Laminar Flow' is utilised for the FE studies. Corresponding to the dimensions of different lattice architectures enlisted in Table 1, unit cells were modeled stepby-step using the in-built 3D geometric modeling tool within COMSOL Multiphysics. Figure 2 showcases each of these unit lattice-cells. Mimicking the actual heat sink environment, lattice- 
cell array of five unit cells were placed on a polymer base plate having a thickness of $0.5 \mathrm{~mm}$. A fluid domain enclosing the lattices and base plate has been created with inlet and exit domains having a volume of $3.5 \mathrm{~mm} \times 3.5 \mathrm{~mm} \times 4.0 \mathrm{~mm}$ each as schematically illustrated in Fig. 3 (a). Focusing on high strength to weight ratio lattice architectures for heat sink applications, polypropylene (PP) was chosen as the basis material for simulations. Air is taken as the convective fluid. Snapshot of the computational domain in case of SC-truss lattice is shown in Fig. 3 (b).
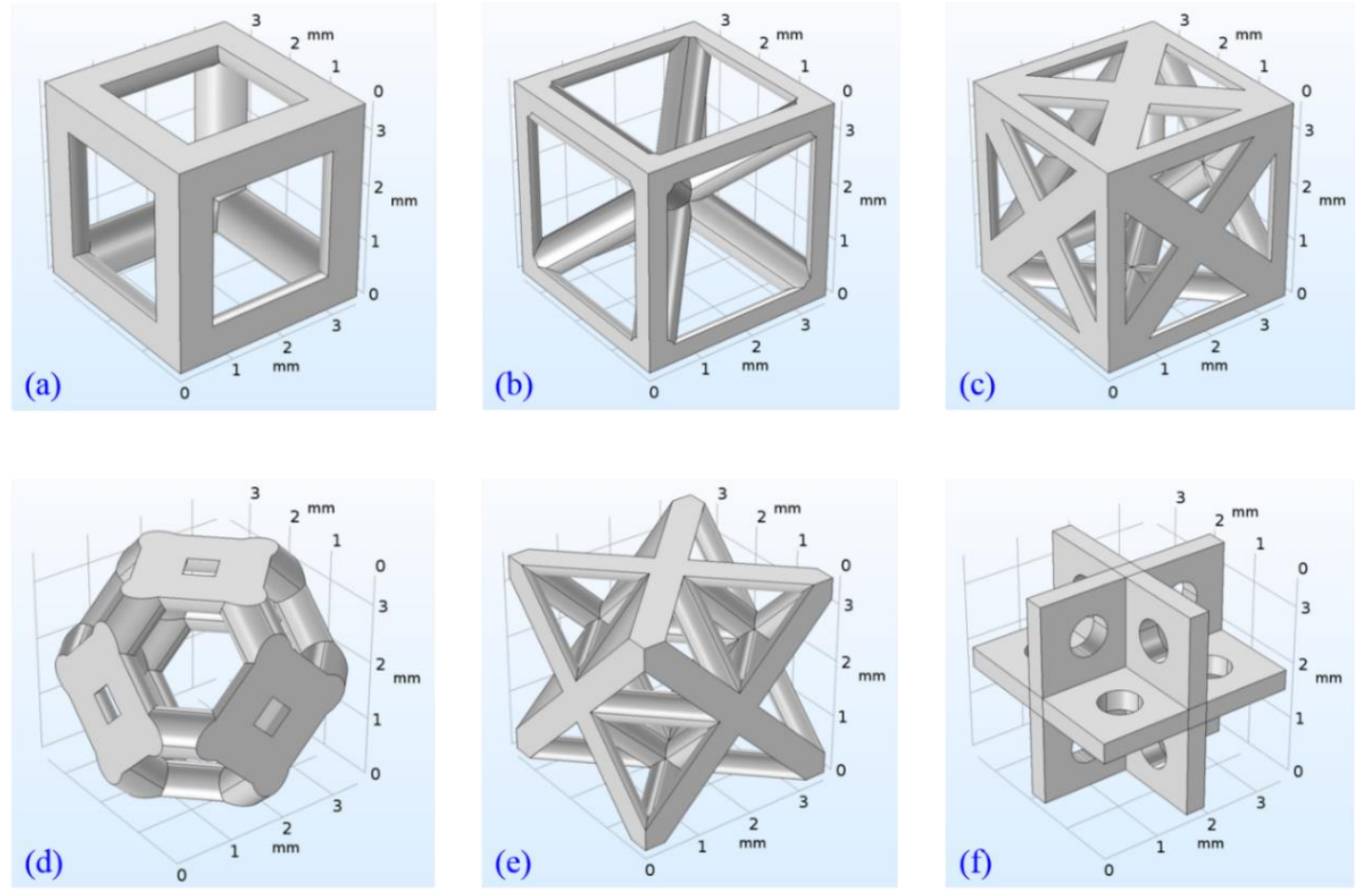

Figure 2: Geometric models of (a) SC-truss (b) SC-BCC-truss (c) SC-FCC-truss (d) Kelvin (e) Octet (f) SC-plate lattices 




Figure 3: (a) Schematic of the computational domain (b) COMSOL Multiphysics snapshot for SCtruss lattice-cell array

A constant temperature boundary condition is imposed to the bottom surface of the base plate $(z=0)$ and it transfers heat to the lattice-cells through the surfaces in contact $\left(z^{+}\right.$direction). The other end of heat sink ( $z^{+}$direction) is considered adiabatic. The fluid is made to flow in the $x^{+}$direction entering the inlet at a specific velocity and temperature that is lower than the bottom wall temperature and exiting at atmospheric pressure. The domain walls along the $y^{+}$and $y^{-}$directions were considered to exhibit thermo-fluid symmetry. These boundary conditions are summarized in Table 2. 
Table 2: Computational boundary conditions

\begin{tabular}{|c|c|c|c|c|}
\hline \multirow{3}{*}{$\begin{array}{l}\text { Location } \\
\text { Fluid inlet }\end{array}$} & \multicolumn{4}{|c|}{ Boundary condition } \\
\hline & \multicolumn{2}{|c|}{ 'Laminar Flow' module } & \multicolumn{2}{|c|}{ 'Heat Transfer in Solids' module } \\
\hline & $\begin{array}{c}\text { Inlet } \\
\text { velocity }\end{array}$ & $\mathrm{u}=-\mathrm{U}_{\mathrm{o}} \mathrm{n}$ & $\begin{array}{c}\text { Inlet } \\
\text { temperature }\end{array}$ & $T=T_{o}$ \\
\hline Fluid outlet & $\begin{array}{c}\text { Atmospheric } \\
\text { pressure }\end{array}$ & $\begin{array}{l}{[-p I} \\
+\mu_{f}(\nabla u \\
\left.\left.+(\nabla u)^{T}\right)\right] n \\
=-\widehat{p_{o}} n \\
\widehat{p_{o}} \leq p_{o}\end{array}$ & Adiabatic & $-n \cdot q=0$ \\
\hline Base plate & & & $\begin{array}{l}\text { Constant } \\
\text { temperature }\end{array}$ & $T=T_{b}$ \\
\hline $\begin{array}{l}\text { Lattice-cell } \\
\text { geometry }\end{array}$ & No-slip & $\mathrm{u}=0$ & Solid-fluic & ermal interface \\
\hline $\begin{array}{l}\text { Fluid domain } \\
\text { walls in } z^{+} \\
\text {and } z^{-} \\
\text {directions }\end{array}$ & No-slip & $\mathrm{u}=0$ & $\begin{array}{l}\text { Thermal } \\
\text { insulation }\end{array}$ & $-n \cdot q=0$ \\
\hline $\begin{array}{l}\text { Fluid domain } \\
\text { walls in } y^{+} \\
\text {and } y^{-} \\
\text {directions }\end{array}$ & Symmetry & $\begin{array}{c}\mathrm{u} \cdot \mathrm{n}=0 \\
\mathrm{~K}-(\mathrm{K} \cdot \mathrm{n}) \mathrm{n}=0 \\
\mathrm{~K} \\
=\left[\mu_{f}(\nabla u\right. \\
\left.\left.+(\nabla u)^{T}\right)\right] n\end{array}$ & Symmetry & $\begin{array}{c}\mathrm{u} \cdot \mathrm{n}=0 \\
\mathrm{~K}-(\mathrm{K} \cdot \mathrm{n}) \mathrm{n}=0 \\
\mathrm{~K} \\
=\left[\mu_{s}(\nabla u\right. \\
\left.\left.+(\nabla u)^{T}\right)\right] n\end{array}$ \\
\hline
\end{tabular}

The single phase, steady-state heat transfer equation employed to evaluate the heat transfer in the solid and fluid domain is given by,

$$
\rho C_{p} u \cdot \nabla T+\nabla \cdot(-k \nabla T)=\bar{Q}
$$


where, $\rho$ is the density, $C_{p}$ is the specific heat, $u$ is the velocity, $T$ is the temperature, $k$ is the thermal conductivity and $\bar{Q}$ is the heat source. The values depend on the domain under consideration, that is, whether solid or fluid.

The incompressible, laminar flow of fluid complies with the following equations,

$$
\begin{aligned}
& \rho_{f}(u \cdot \nabla) u=\nabla \cdot\left[-p I+\mu_{f}\left(\nabla u+(\nabla u)^{T}\right)\right]+F \\
& \rho_{f} \nabla \cdot(u)=0
\end{aligned}
$$

where, $\mu_{f}$ is the fluid dynamic viscosity, $p$ is the pressure and $F$ is the body force per unit volume. The in-built stationary linear system iterative solver GMRES was employed to solve the aforementioned governing equations in conjunction with the boundary conditions. The mesh generator discretizes the solid and fluid domains into tetrahedral, hexahedral and pyramid elements. Mesh convergence study was conducted and, accordingly, number of elements required for mesh independent response vary between 0.42 and 2.0 million for the different lattice-cell architectures.

Initially, we validate our numerical model employing Kelvin-cell and Octet truss lattice structures with the extant works. In case of Kelvin-cell, the results are bench-marked with the experimental data reported in literature [45-49]. In contrast, Octet truss lattices have not been experimentally tested thus far (owing to the complexity of manufacture - now proposed to be realized via 3D printing) but have been simulated explicitly by Ekade and Krishnan [37]. Unlike the present numerical model, both the studies explicitly take into account the heat transfer and flow in the fluid domain only which is obtained after subtracting the solid geometry from the bounding box. Kelvin and Octet topologies, having same geometrical features as in references [35] (ideal) and [37], were re-created and simulated under the same boundary conditions. Aluminium and air were taken as the solid and fluid domains respectively.

The thermo-hydraulic data obtained from the present model is compared to that of the extant experimental and numerical data in Fig. 4. Since Kelvin-cell is considered as the idealized structure most closely representing the open-cell foam architecture, experimental data for the latter has been used to validate our model. It can be seen from Fig. 4 (a) that the present model predicts the volumetric Nusselt number within the range of experimental data reported by Younis and Viskanta [45] and Hwang et al. [46] for various pore Reynolds number. In case of the lasiello 
et al. [35], our model prediction is closer to the Nusselt number of the ideal Kelvin structure than that of the corresponding real structure. On the contrary, Fig. 4 (b) shows that the simulated pressure drop per unit length follows the trendline of the real structure than the ideal one of lasiello et al. [35]. Nevertheless, pressure drop per unit length predictions in this work are in accordance with that of the experimental results of Dukhan [48] and Wu et al. [49]. Referring to Fig. 4 (c) and (d), both permeability-based Nusselt number and friction factor data predicted for Octet-cell by the present model closely match those obtained by Ekade and Krishnan [37], albeit a small deviation is observed at high Reynolds number.


Figure 4: Validation of the present computational model using extant experimental and numerical heat transfer and pressure drop data: Kelvin-cell [(a) and (b)] and Octet-cell [(c) and (d)] 


\section{Results and Discussion}

The thermo-hydraulic performance of different lattice-cell architectures under consideration is presented in this section. Convective fluid flow was simulated at low Reynolds number in the range of $50-360$ which corresponds to air velocity in the range of $0.25-1.5 \mathrm{~m} / \mathrm{s}$. The air inlet temperature was kept at $20^{\circ} \mathrm{C}$. Polypropylene, the basis material, is considered to have a density of $905 \mathrm{~kg} / \mathrm{m}^{3}$, specific heat of $1920 \mathrm{~J} / \mathrm{kgK}$ and thermal conductivity of $0.1720 \mathrm{~W} / \mathrm{mK}$ while the fluid (here, air) has temperature dependent properties. Bottom surface of the base plate was maintained at a constant temperature of $75^{\circ} \mathrm{C}$ which is well below the melting point of polypropylene $\left(175^{\circ} \mathrm{C}\right)[50]$.

The fluid exit temperatures with increase in superficial velocity is shown in Fig. 5 . The temperatures were taken as a weighted average of the temperature at the exit surface. It can be observed that at lower velocities, the exit temperature of air is the highest for Octet lattice followed by SC-plate, Kelvin, SC-BCC-truss, SC-FCC-truss and the lowest for SC-truss architecture. On the other hand, at higher velocities, SC-BCC-truss, SC-plate and Kelvin lattices exhibit higher fluid exit temperatures than the Octet lattice.



Figure 5: Fluid exit temperature as a function of inlet fuid velocity for different lattice-cell architectures for $T_{b}=75^{\circ} \mathrm{C}$ and $T_{f, \text { in }}=20^{\circ} \mathrm{C}$ 
A careful examination of temperature contour plot at the exit section of the fluid domain (see Fig. 6) provides a better insight into heat transfer characteristics of various lattice architectures. For all lattices, except for SC-plate, high temperature fluid regions are seen closer to base plate while the distribution of air temperature towards the insulated top is almost same as the inlet temperature rendering upper half of the architecture ineffective. Moreover, the temperature distribution is evidently dependent on the orientation and inter-connection of the ligaments. For instance, Kelvin and SC-BCC-truss show a peak at the centre since the fluid is able to pick up more heat through the intesecting struts at the centre of their architectures. Octet cell imparts the highest temperature closer to the base plate. On the contrary, such high temperatures are not achieved in case of SC-plate, instead, the temperatures are uniformly distributed across the lattice topology resulting in high weighted average temperature at the exit.
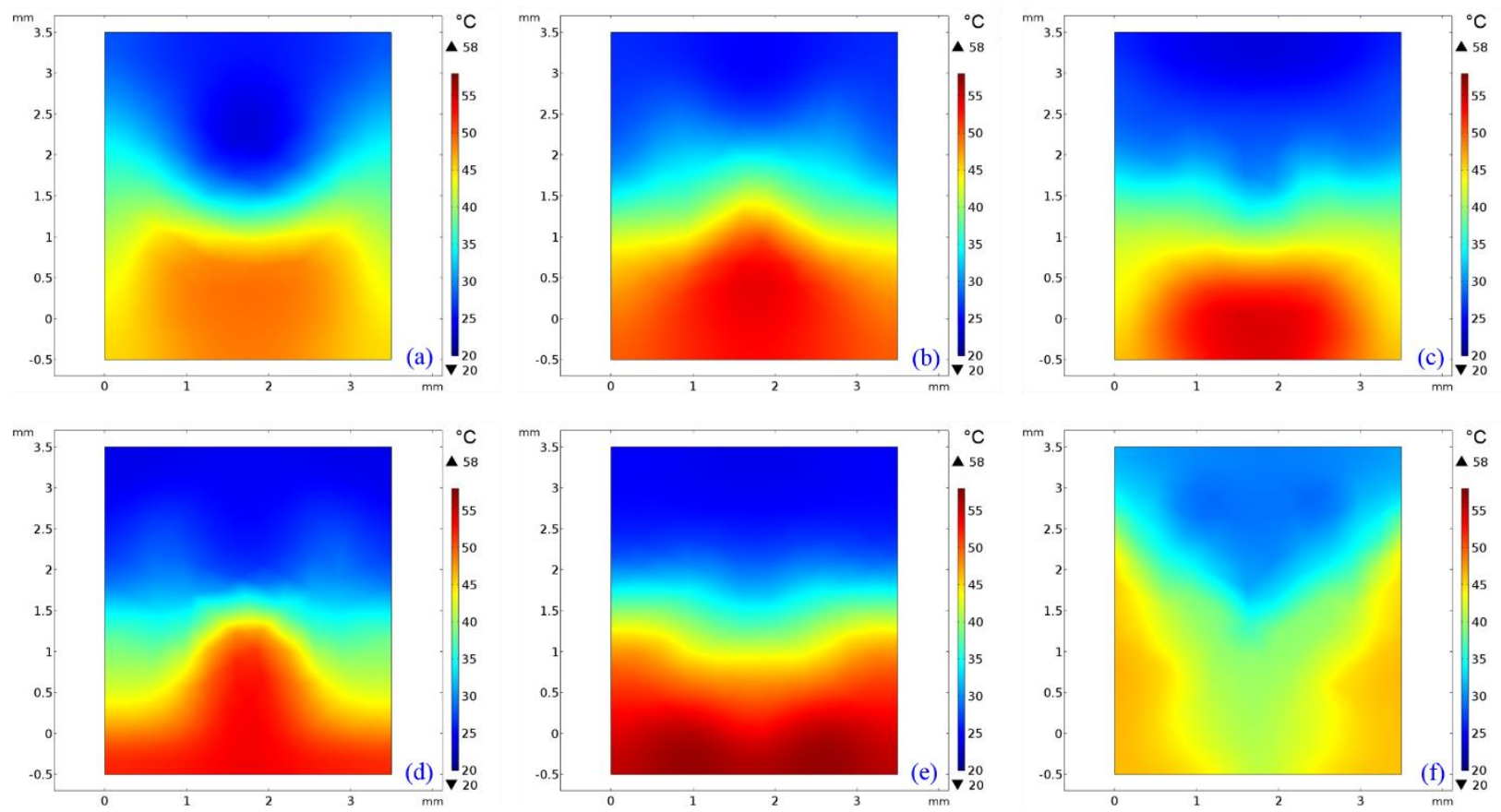

Figure 6: Contour plot of fluid exit temperature for (a) SC-truss (b) SC-BCC-truss (c) SC-FCC-truss (d) Kelvin (e) Octet (f) SC-plate lattice-cells at $u=0.5 \mathrm{~m} / \mathrm{s}, T_{b}=75^{\circ} \mathrm{C}$ and $T_{f, \text { in }}=20^{\circ} \mathrm{C}$

Using the exit fluid temperature data thus obtained, convective heat transfer coefficient was calculated (see Fig. 7 (a)) using Eq. (4) given below. 


$$
h=\frac{\dot{m} C_{p}\left(T_{f, \text { out }}-T_{f, \text { in }}\right)}{A_{b} \Delta T_{L M T D}}
$$

where, $\dot{m}$ is the fluid mass flow rate and $\Delta T_{L M T D}$ is the logarithmic mean temperature difference obtained by the expression $\Delta T_{L M T D}=\frac{T_{f, o u t}-T_{f, i n}}{\ln _{\frac{T_{b}-T_{f, \text { in }}}{T_{b^{-T}} \text {, out }}}}$.

It can be observed from Fig. 7 (a) that the heat transfer coefficient increases with increase in mass flow rate of the air. Octet lattice has the highest heat transfer coefficient at the lowest velocity while it's the least for SC-truss. At the highest velocity considered, SC-BCC-truss, SC-plate, Kelvin, Octet, SC-FCC-truss and SC-truss can be ranked in the order of decreasing heat transfer coefficient. It is interesting to note that the heat transfer performance of the lattice-cells is actually not in accordance with their respective surface areas mentioned in Table 1. According to the Newton's law of cooling, the heat transfer rate is directly proportional to the heat exchanger surface area [51]. Nevertheless, it is apparent from Fig. 7 (a) that the architecture of the latticecell governs the thermal performance.

Apart from the solid-fluid heat transfer surface area, even the contact surface area between the fin and base plate is a significant parameter effecting the conductive heat flow path. Recalculating the heat transfer coefficient employing Eq. (4), but based on the contact surface area, results in Fig. 7 (b). It is evident that, not only the convective surface area, but even possessing a larger contact surface area does not guarantee a high heat transfer rate. In spite of SC-FCC-truss having the maximum surface area density as well as the highest contact area (Table 1), it doesn't show improved performance. On the contrary, Kelvin cell has the lowest contact area after SCplate along with the least convective surface area but provides the second-best heat transfer coefficient values. The heat transfer coefficient is therefore greatly dependent on the architecture and its conductive-convective route. In this case, an obvious next question is which one of these architectures is hydraulically efficient?

To address this, the pressure drop per unit length of fluid flowing over different lattice architectures at varying mass flow rates is presented in Fig. 8. It can be observed that SC-plate, possessing only circular holes for fluid flow (Fig. 1f), is associated with considerably high pressure drop in comparison to the other lattice architectures. The relatively steep increase in pressure drop with increase in mass flow rates is bound to occur at even higher fluid velocities. On the 
other hand, the central void space in SC-truss (Fig. 1a) imparts a freer flow of fluid resulting in the lowest pressure drop. Presence of intersecting struts in the remaining lattices acts as an added hindrance to the fluid flow leading to higher pressure drop than the SC-truss lattice. While SC-BCC-truss exhibits the second-lowest pressure drop over the entire range of mass flow rates considered, the highest pressure drop after SC-plate is observed for Octet and SC-FCC-truss lattices at the minimum and maximum flow rate respectively.
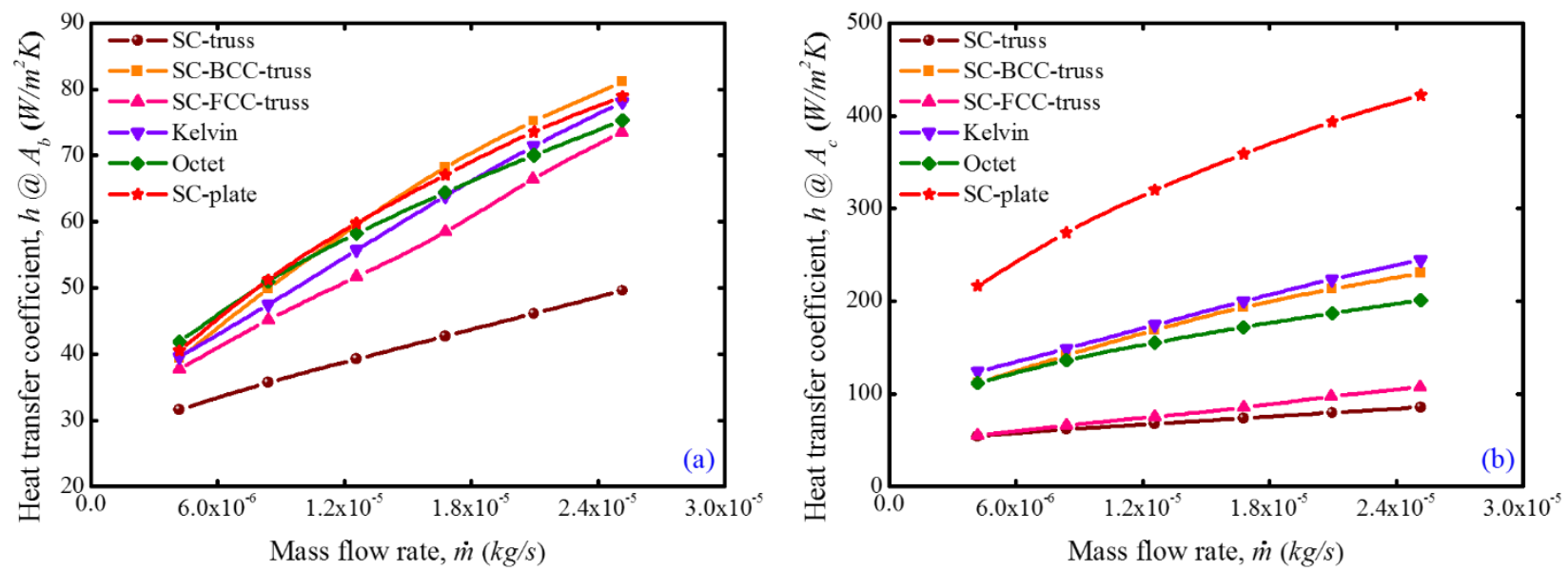

Figure 7: Variation of heat transfer coefficient with mass flow rate for different lattice-cell architectures based on (a) base plate surface area (b) contact surface area between lattice structure and base plate with $T_{b}=75^{\circ} \mathrm{C}$ and $T_{f, \text { in }}=20^{\circ} \mathrm{C}$

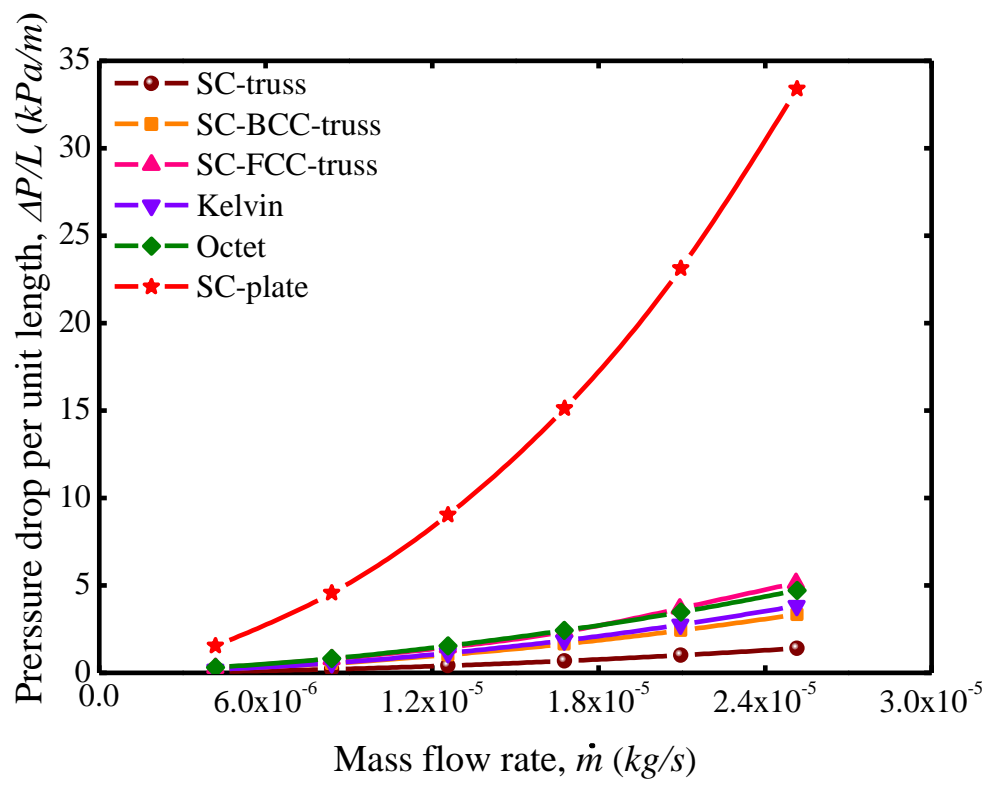


Figure 8: Variation of pressure drop per unit length as a function of mass flow rate for different lattice-cell architectures

Using the data presented in Fig. 7 (a) and Fig. 8, more useful non-dimensional quantities, namely; Colburn factor $j$ and Fanning friction factor $f$, are determined using Eqs. (5) and (6) respectively.

$$
\begin{aligned}
& j=\frac{N u \cdot \operatorname{Pr}^{-1 / 3}}{R e} \\
& f=\frac{\Delta P}{L}\left(\frac{D_{h}}{2 \rho_{f} u^{2}}\right)
\end{aligned}
$$

where, $N u=\left(h D_{h}\right) / k_{f}, R e=\left(\rho_{f} u D_{h}\right) / \mu$ and the hydraulic diameter $D_{h}$ is based on the duct cross-sectional dimensions. The variation of these two parameters is plotted against dimensionless Reynolds number in Fig. 9 (a) and Fig. 9 (b). It can be seen from these figures that the performance of various lattice-cell architectures follows the same trend as in Fig. 7 (a) and Fig. 8 respectively. Yet another non-dimensional factor that provides a better insight into the performance based on both heat transfer and pressure drop characteristics is known as "flow area goodness factor" and is defined as the ratio between $j$ and $f$ factor [52]. The variation in area goodness factor against the Reynolds number is shown in Fig. 10. Despite its poor thermal performance, SC-truss exhibits the highest $j / f$ ratio owing to its low friction factor values. Conversely, the huge pressure drop associated with SC-plate lattice overshadows its high heat transfer characteristics. With respect to the design of heat sink, such high pumping power requirements are not desirable. SC-BCC-truss is observed to evince $j$ factor almost on par with that of Octet lattice (see, Fig. 9a) along with second-lowest friction factor data (see, Fig. 9b). If both heat transfer and pressure drop characteristics are considered, SC-BCC-truss seems to best serve as a heat sink fin amongst all lattice-cell architectures for flow conditions considered here. 

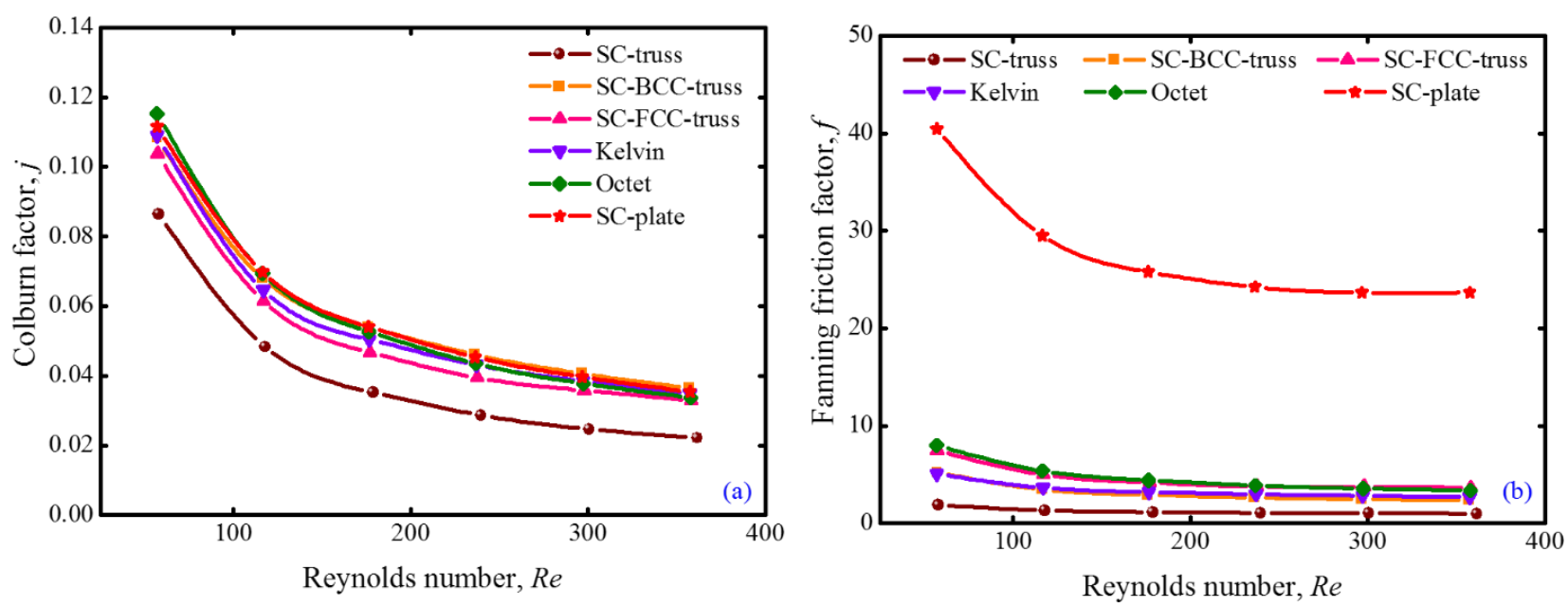

Figure 9: Variation of (a) Colburn $j$ factor (b) Fanning friction factor $f$ over a range of Reynolds number for different lattice-cell architectures subjected to constant temperature base plate conditions

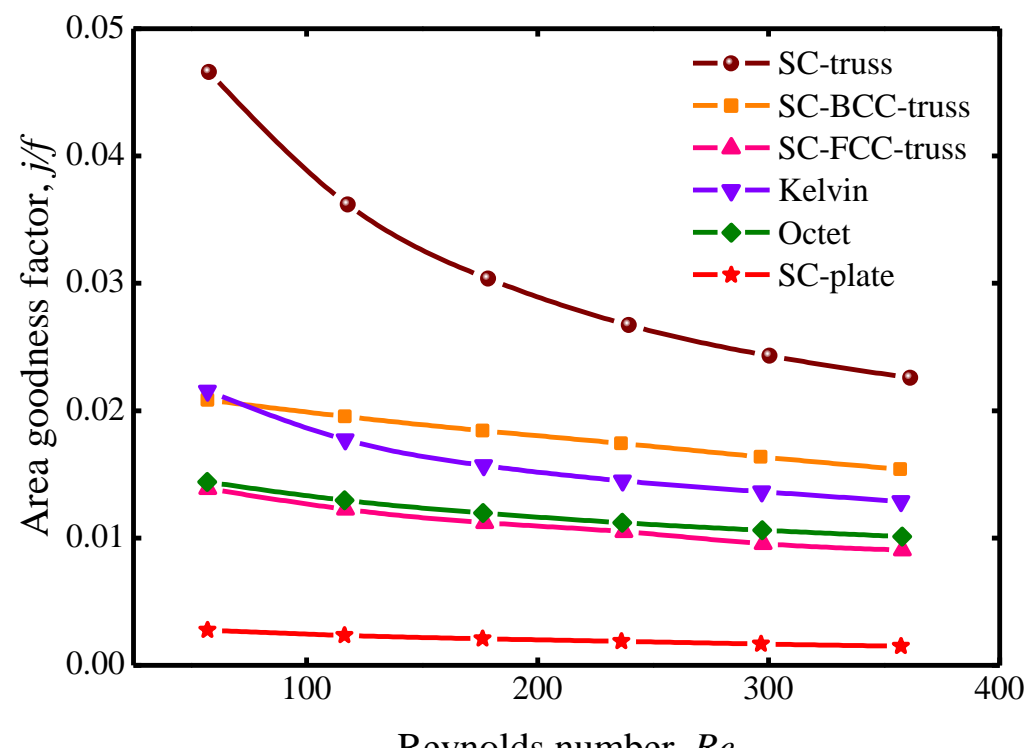

Reynolds number, $R e$

Figure 10: Variation of area goodness factor $j / f$ with Reynolds number for different lattice-cell architectures

One of the key advantages of periodic cellular architectures is that their performance can be tailored by changing the architectural parameters such as the porosity (conversely, relative density). Foregoing discussion focused on lattices having a relative density of 0.23 (porosity of 
$77 \%)$. The performance of different lattices were examined by varying the relative density from 0.1 to 0.25 (90 to $75 \%$ porosity) and the resulting heat transfer and pressure drop characteristics are plotted in Fig. 11 (a) and Fig. 11 (b) respectively. The analysis considered an inlet fluid velocity of $0.5 \mathrm{~m} / \mathrm{s}$. SC-plate architecture was not included in the analysis owing to its considerably high pressure drop characteristics. It can be observed from Fig. 11 that increase in porosity of latticecell architecture decreases the heat transfer rate as well as the pressure drop. This is because, for a constant unit cell volume, higher porosity imparts lower interactive surface area. The highest heat transfer rate is rendered by Octet lattice whereas heat transfer rate is the lowest for the SC-truss. SC-BCC-truss, Kelvin and SC-FCC-truss showcase intermediate heat transfer rates. While all architectures depict gradual raise in pressure drop, a sudden increase is observed for SC-FCC-truss lattice at higher relative density (lower porosity).
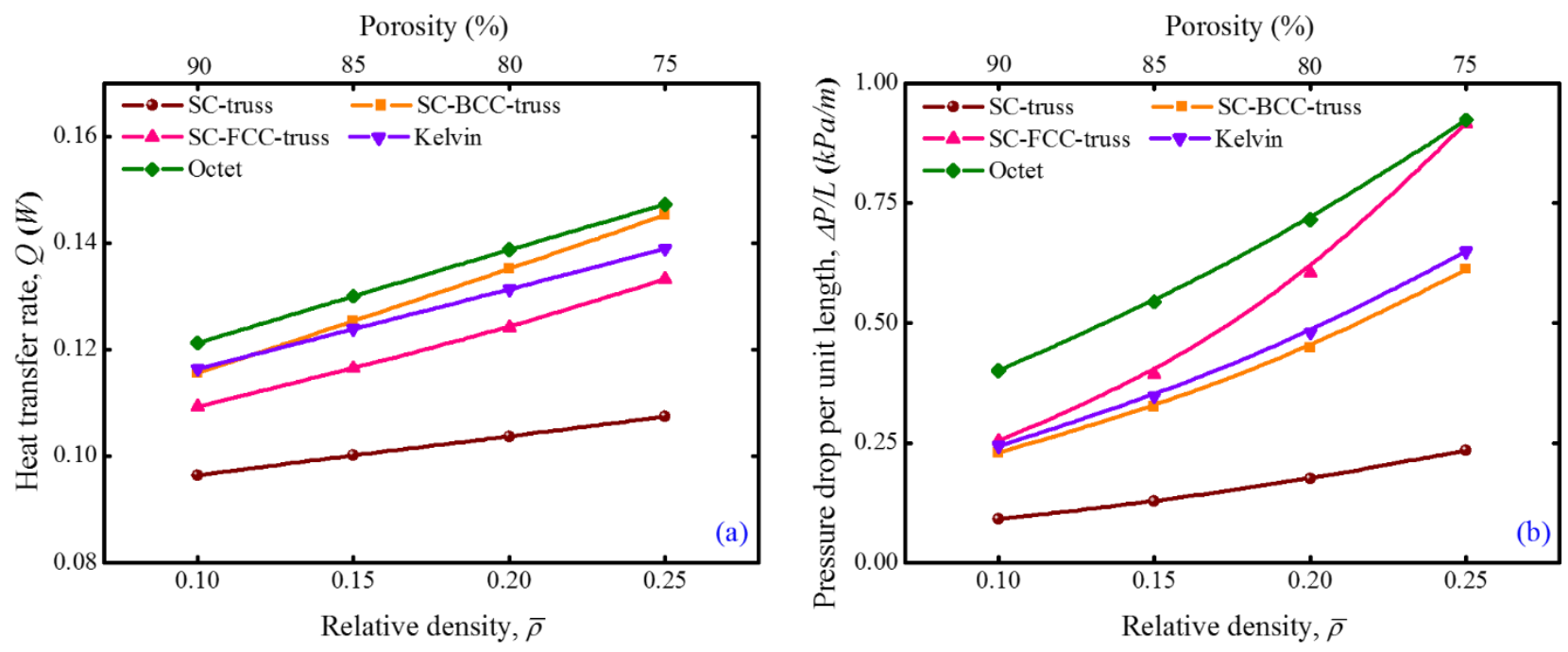

Figure 11: Variation of (a) heat transfer rate and (b) pressure drop per unit length as a function of relative density (or porosity) at $u=0.5 \mathrm{~m} / \mathrm{s}, T_{b}=75^{\circ} \mathrm{C}$ and $T_{f, \text { in }}=20^{\circ} \mathrm{C}$

Explicitly focusing on heat sink applications with imposed weight limitations and environmental considerations such as corrosion, polypropylene is chosen as the lattice-cell material inherently accepting the fact that this thermoplastic has low thermal conductivity. Although the choice of metals can be beneficial in terms of high thermal conductivity, their utility is limited by high specific weight. Keeping heat sink weight as the governing criterion, the thermal performance for chosen architectures is evaluated by varying basis material density and thermal conductivity and 
the results are summarized in terms of specific convective heat transfer rate and nondimensional exit fluid temperature expressed as $\left(\frac{T_{b}-T_{f, o u t}}{T_{b}-T_{f, \text { in }}}\right)$. These performance indicators as a function of basis material thermal conductivity are presented in Fig 12. We chose architectures which exhibit the best and least heat transfer rates from Fig. 11 (a) and the performance of selected Octet and SC-truss lattice-cells at a flow velocity of $0.5 \mathrm{~m} / \mathrm{s}$ is analysed. The physical parameters chosen are same as those mentioned in Table 1. The materials chosen for comparison with polypropylene include high thermal conductivity metal - aluminium $\left(\rho_{s}=2700 \mathrm{~kg} / \mathrm{m}^{3}\right.$, $\left.k_{s}=237 \mathrm{~W} / \mathrm{mK}\right)$, low thermal conductivity metal - stainless steel $\left(\rho_{s}=7850 \mathrm{~kg} / \mathrm{m}^{3}, k_{s}=\right.$ $16.2 \mathrm{~W} / \mathrm{mK})$ and ceramic - alumina $\left(\rho_{s}=3850 \mathrm{~kg} / \mathrm{m}^{3}, k_{s}=29 \mathrm{~W} / \mathrm{mK}\right)$.
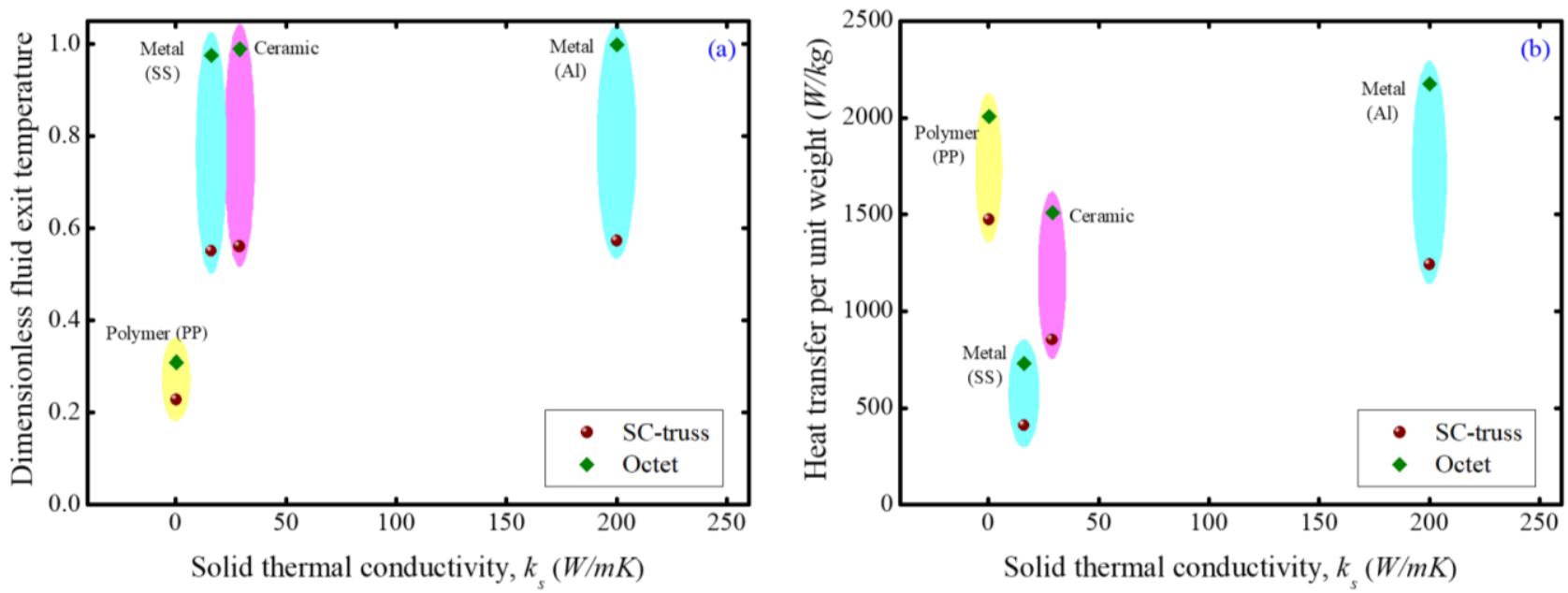

Figure 12: Variation of (a) dimensionless fluid exit temperature (b) heat transfer rate per unit mass as a function of basis material thermal conductivity for SC-truss and Kelvin lattices for $77 \%$ porosity at $u=0.5 \mathrm{~m} / \mathrm{s}, T_{b}=75^{\circ} \mathrm{C}$ and $T_{f, \text { in }}=20^{\circ} \mathrm{C}$

It can be observed from Fig.12 (a) that the fluid exit temperature increases with increase in thermal conductivity of chosen material. In low thermal conductivity range, higher values of material conductivity can be reasonably beneficial. Nevertheless, multi-fold increase in the thermal conductivity of the material does not result in proportional increase of specific heat transfer rate (Fig. 12 (b)). For instance, aluminium in spite of having nearly fifteen times higher thermal conductivity than stainless steel, contributes only to marginal increase in exit fluid temperature. It can be seen from Fig. 12 (b) that the low density low thermal conductivity 
polypropylene (PP) exhibits a specific heat transfer rate comparable to high density high thermal conductivity aluminium. As a matter of fact, for SC-truss architecture, the specific heat transfer rate is slightly higher for PP than for aluminium. Furthermore, the pronounced effect of lattice architecture for high conductivity materials can be distinctly seen from Fig. 12. As compared to SC-truss, Octet lattice results in $75 \%$ increase of specific convective heat transfer rate for aluminium as opposed to only $36 \%$ increase for PP. The performance of polymer such as PP can be further enhanced if beneficial attributes such its low density and controlled lattice architecture are combined with high thermal conductivity. The latter has been made possible by the addition of thermally conductive micro- and/or nano-fillers such as metallic nanoparticles, short carbon fibres, carbon nanotubes and graphene [42].

Lastly, to further elucidate the merits of lattice-cell architectures, their thermal performance is compared to that of the non-traditional extended surfaces, namely, microchannel and stochastic open-cell foams. The data for microchannel heat sinks is taken from Sui et al. [53], wherein numerical studies of periodic wavy microchannels with rectangular cross-section have been conducted for constant wall temperature conditions. They evaluated the heat transfer coefficient based on the conduction area at the base. Accordingly, values from Fig. 7 (b) were expressed as Nusselt number (see Fig. 13 (a)). It can be observed from Fig. 13 (a), that the microchannel heat sink shows inferior thermal performance compared to SC-plate, Kelvin, SC-BCC-truss and Octet lattices but exhibits better performance than the SC-truss and SC-FCC-truss lattices. However, for Reynolds number lower than 100, all lattice-cell heat sinks showcase superior heat transfer properties to the microchannel investigated by Sui et al. [53]. In terms of the hydraulic performance, microchannel investigated by Sui et al. [53] exhibits lower pressure drop than that of the simulated lattices, as shown in Fig. 13 (c).

Thereafter, experimental data obtained by Amani et al. [54] for $20 \%$ relative density open-cell copper foam is compared to the simulated polymer lattice-cell architectures having $23 \%$ relative density. The Nusselt number was calculated from the heat transfer coefficient based on the base plate area (Fig. 7a), as in reference [54], and is graphically shown in Fig. 13 (b). Except for the SCtruss lattice, other architectures perform at par, if not better, with the stochastic foam. Slope of 
the trend lines indicate that at higher Reynolds number, performance of periodic geometries such as SC-BCC-truss, SC-plate and Kelvin lattices will be higher than that of the stochastic foams.
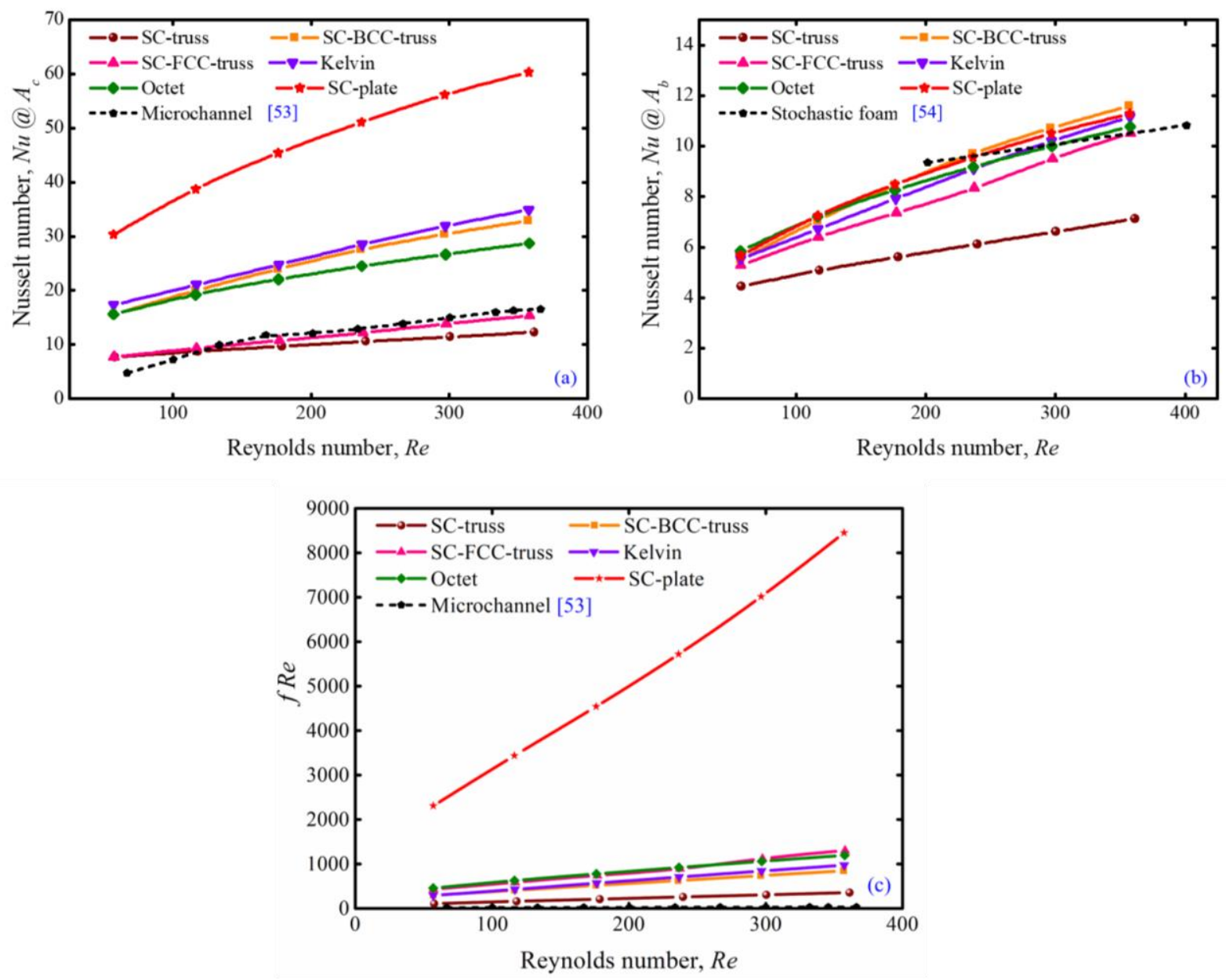

Figure 13: Comparison of lattice-cell fins with respect to (a) (c) microchannel (b) stochastic open-cell foam

\section{Conclusions}

Finite element analysis of AM-realizable mesostructured periodic lattice-cell architectures was conducted to determine their heat transfer and pressure drop characteristics. In view of the high surface area-to-volume ratio requirements, cubic-cell, Kelvin-cell and Octet-cell topologies were investigated. The fluid is assumed to be laminar ( $R e=50$ to 360) over an array of lattice-cells subjected to constant temperature boundary condition on one of its surfaces, thereby mimicking the heat sink condition. The conclusions drawn from this study are concisely enlisted as follows: 
- Octet topology imparts the highest heat transfer rate at the lowest fluid velocity while SCBCC-truss outperforms other architectures as the fluid velocity increases.

- Pressure drop obtained for plate-type lattices is considerably higher than the truss-type geometries. Regardless of its high heat transfer performance, designer may perhaps refrain from using plate-type lattices so as to evade extremely high pumping power costs.

- Although SC-truss lattice exhibits the least pressure drop, its heat transfer performance is also comparatively the lowest.

- Keeping the extreme cases of SC-plate and SC-truss lattices aside, SC-BCC-truss provides an optimum combination of high heat transfer rate and low pressure drop leading to its optimum area goodness factor ( $j / f$ value).

- Lightweight polymer lattice heat sinks, in spite of having low thermal conductivity, have comparable specific convective heat transfer rate with respect to high thermal conductivity, bulk metals.

- SC-plate, Kelvin, SC-BCC-truss and Octet lattices exhibit better thermal performance than the microchannel heat sinks. At higher Reynolds number, periodic geometries such as SCBCC-truss, SC-plate and Kelvin lattices show higher thermal performance than that of the stochastic foams.

The heat transfer performance of polymer heat sinks can be further enhanced if their beneficial attributes such the low density and tailorable architecture are combined with thermally conductive micro- and/or nano-fillers such as metallic nanoparticles, short carbon fibers, carbon nanotubes and graphene as in cellular nanocomposites. Emerging advances in 3D printing will enable fabrication of micro- and nano-architected ultrahigh conductive cellular composites referred to as thermal metamaterials.

\section{Acknowledgment}

The authors would like to thank Abu Dhabi National Oil Company (ADNOC) for providing the research grant under Award No: EX2016-000010. SK would like thank the University of Glasgow for the start up grant. 







$\begin{array}{ll}\bar{\rho} & \text { Relative density } \\ \rho & \text { Density }\left(\mathrm{kg} / \mathrm{m}^{3}\right) \\ \mu & \text { Dynamic viscosity }\left(\mathrm{Ns} / \mathrm{m}^{2}\right)\end{array}$

\section{Subscript}

$f \quad$ fluid

K permeability

in inlet

$s \quad$ solid

out exit

\section{References}

1. Vaezi M., Seitz H., Yang S., A review on 3D micro-additive manufacturing technologies, The International Journal of Advanced Manufacturing Technology 67 (2013) 1721-1754.

2. MacDonald E., Wicker R., Multiprocess 3D printing for increasing component functionality, Science 353 (6307) (2016) aaf2093.

3. Ngo T.D., Kashani A., Imbalzano G., Nguyen K.T.Q., Hui D., Additive manufacturing (3D printing): A review of materials, methods, applications and challenges, Composites Part $B$ 143 (2018) 172-196.

4. Dugbenoo E., Arif M.F., Wardle B.L., Kumar S., Enhanced bonding via additive manufacturing-enabled surface tailoring of 3D printed continuous-fiber composites, Advanced Engineering Materials 20 (12) (2018) 1800691.

5. Ashby M., Designing architectured materials, Scripta Materialia 68 (2013) 4-7.

6. Brechet Y., Embury J.D., Architectured materials: Expanding materials space, Scripta Materialia 68 (2013) 1-3.

7. Schaedler T.A., Jacobsen A.J., Torrents A., Sorensen A.E., Lian J., Greer J.R., Valdevit L., Carter W.B., Ultralight metallic microlattices, Science 334 (6058) (2011) 962-965. 
8. Zhu C., Han T.Y., Duoss E.B., Golobic A.M., Kuntz J.D., Spadaccini C.M., Worsley M.A., Highly compressible 3D periodic graphene aerogel microlattices, Nature Communications 6 (2015) 6962-1-10.

9. Kessler, J., Balc N., Gebhardt A., Abbas, K., Basic research on lattice structures focused on the reliance of the cross sectional area and additional coatings, Proceedings of the MATEC Web of Conferences 94 (2017) 03008.

10. Yu X., Zhou J., Liang H., Jiang Z., Wu L., Mechanical metamaterials associated with stiffness, rigidity and compressibility: A brief review, Progress in Materials Science 94 (2018) 114173.

11. Calise G.J., Saigal A., Anisotropy and failure in octahedral lattice structure parts fabricated using the FDM technology, Proceedings of the ASME International Mechanical Engineering Congress and Exposition, November 3-9, 2017, Tampa, Florida, USA, Paper No. IMECE201770904.

12. Despres N., Cyr E., Mohammadi M., A performance metric for additively manufactured microlattice structures under different loading conditions, Proceedings of the Institution of Mechanical Engineers Part L: Journal of Materials: Design and Applications 0 (2018) 1-16 DOI: $10.1177 / 1464420718793916$.

13. Leary M., Mazur M., Elambasseril J., McMillan M., Chirent T., Sun Y., Qian M., Easton M., Brandt M., Selective laser melting (SLM) of AISi12Mg lattice structures, Materials and Design 98 (2016) 344-357.

14. Tancogne-Dejean T., Diamantopoulou M., Gorji M.B., Bonatti C., Mohr D., 3D plate-lattices: An emerging class of low-densitymetamaterial exhibiting optimal isotropic stiffness, Advanced Materials 30 (45) (2018) 1803334-1-6.

15. Deshpande V.S., Fleck N.A., Ashby M.F., Effective properties of the octet-truss lattice material, Journal of the Mechanics and Physics of Solids 49 (2001) $1747-1769$.

16. Zheng X., Lee H., Weisgraber T.H., Shusteff M., DeOtte J., Duoss E.B., Kuntz J.D., Biener M.M., Ge Q., Jackson J.A., Kucheyev S.O., Fang N.X., Spadaccini C.M., Ultralight, ultrastiff mechanical metamaterials, Science 344 (6190) (2014) 1373-1377. 
17. Mohsenizadeh M., Gasbarri F., Munther M., Beheshti A., Davami K., Additivelymanufactured lightweight Metamaterials for energy absorption, Materials and Design 139 (2018) 521-530.

18. Maskery I., Sturm L., Aremu A.O., Panesar A., Williams C.B., Tuck C.J., Wildman R.D., Ashcroft I.A., Hague R.J.M., Insights into the mechanical properties of several triply periodic minimal surface lattice structures made by polymer additive manufacturing, Polymer 152 (2018) 62-71.

19. Rashed M.G., Ashraf M., Mines R.A.W., Hazell P.J., Metallic microlattice materials: A current state of the art on manufacturing, mechanical properties and applications, Materials and Design 95 (2016) 518-533.

20. Xiong J., Mines R., Ghosh R., Vaziri A., Ma L., Ohrndorf A., Christ H., Wu L., Advanced microlattice materials, Advanced Engineering Materials 17 (9) (2015) 1253-1264.

21. Wadley H., Queheillalt D., Thermal applications of cellular lattice structures, Materials Science Forum 539 (2007) 242-247.

22. Huang Y., Hsu H., Numerical simulation and experimental validation of heat sinks fabricated using selective laser melting for use in a compact LED recessed downlight, Microsystem Technologies 1/2019 16-05-2018 https://doi.org/10.1007/s00542-018-3943-x.

23. Saleh M.S., Li J., Park J., Panat R., 3D printed hierarchically-porous microlattice electrode materials for exceptionally high specific capacity and areal capacity lithium ion batteries, Additive Manufacturing 23 (2018) 70-78.

24. Mullen L., Stamp R.C., Brooks W.K., Jones E., Sutcliffe C.J., Selective laser melting: A regular unit cell approach for the manufacture of porous, titanium, bone in-growth constructs, suitable for orthopedic applications, Journal of Biomedical Materials Research Part B Applied Biomaterials 89 (2) (2009) 325-334.

25. Evans A.G., Hutchinson J.W., Fleck N.A., Ashby M.F., Wadley H.N.G., The topological design of multifunctional cellular materials, Progress in Materials Science 46 (2001) 309-327.

26. Gibson L.J., Ashby M.F., 1988, Cellular Solids: Structure and Properties, Pergamon Press, Oxford. 
27. Schaedler T.A., Carter, W.B., Architected Cellular Materials, Annual Review of Materials Research 46 (2016) 187-210.

28. Jafari D., Wits W.W., The utilization of selective laser melting technology on heat transfer devices for thermal energy conversion applications: A review, Renewable and Sustainable Energy Reviews 91 (2018) 420-442.

29. Ho J.Y., Leong K.C., Wong T.N., Experimental and numerical investigation of forced convection heat transfer in porous lattice structures produced by selective laser melting, International Journal of Thermal Sciences 137 (2019) 276-287.

30. Ventola L., Robotti F., Dialameh M., Calignano F., Manfredi, D., Chiavazzo E., Asinari P., Rough surfaces with enhanced heat transfer for electronics cooling by direct metal laser sintering, International Journal of Heat and Mass Transfer 75 (2014) 58-74.

31. Son K.N., Weibel J.A., Kumaresan V., Garimella S.V.,Design of multifunctional lattice-frame materials for compact heat exchangers, International Journal of Heat and Mass Transfer 115 (2017) 619-629.

32. Yan H.B., Zhang Q.C., Lu T.J., Kim T., A lightweight X-type metallic lattice in single-phase forced convection, International Journal of Heat and Mass Transfer 83 (2015) 273-283.

33. Krishnan S., Hernon D., Hodes M., Mullins J., Lyons A.M., Design of complex structured monolithic heat sinks for enhanced air cooling, IEEE Transactions on Components, Packaging and Manufacturing Technology 2 (2) (2012) 266-277.

34. Dukhan N., Suleiman A.S., The thermally-developing region in metal foam with open pores and high porosity, Thermal Science and Engineering Progress 1 (2017) 88-96.

35. Iasiello M., Cunsolo S., Oliviero M., Harris W.M., Bianco N., Chiu W.K.S., Naso V., Numerical analysis of heat transfer and pressure drop in metal foams for different morphological models, ASME Journal of Heat Transfer 136 (2014) 112601-1-10.

36. Moon C., Kim H.D., Kim K.C., Kelvin-cell-based metal foam heat exchanger with elliptical struts for low energy consumption, Applied Thermal Engineering 144 (2018) 540-550.

37. Ekade P., Krishnan S., Fluid flow and heat transfer characteristics of octet truss lattice geometry, International Journal of Thermal Sciences 137 (2019) 253-261. 
38. Wong M., Owen I., Sutcliffe C.J., Puri A., Convective heat transfer and pressure losses across novel heat sinks fabricated by Selective Laser Melting, International Journal of Heat and Mass Transfer 52 (2009) 281-288.

39. Gupta T.K., Choosri M., Varadarajan K.M., Kumar S., Self-sensing and mechanical performance of CNT/GNP/UHMWPE biocompatible nanocomposites, Journal of Materials Science 53 (11) (2018) 7939-7952.

40. Reddy S.K., Kumar S., Varadarajan K.M., Marpu P.R., Gupta T.K., Choosri M., Strain and damage-sensing performance of biocompatible smart CNT/UHMWPE nanocomposites Materials Science and Engineering: C 92 (1) (2018) 957-968.

41. Arif M.F., Kumar S., Gupta T.K., Varadarajan K.M., Strong linear-piezoresistive-response of carbon nanostructures reinforced hyperelastic polymer nanocomposites, Composites Part A: Applied Science and Manufacturing 113 (2018) 141-149.

42. Hussain A.R.J., Alahyari A.A., Eastman S.A., Thibaud-Erkey C., Johnston S., Sobkowicz M.J.,Review of polymers for heat exchanger applications: Factors concerning thermal conductivity, Applied Thermal Engineering 113 (2017) 1118-1127.

43. Kumar S., Wardle B.L., Arif M.F., Strength and performance enhancement of bonded joints by spatial tailoring of adhesive compliance via 3D printing, ACS Applied Materials \& Interfaces 9(1) (2017) 884-891.

44. Kumar S., Ubaid J., Abishera R., Schiffer A., Deshpande V.S., Tunable energy absorption characteristics of architected honeycombs enabled via additive manufacturing, ACS Applied Materials \& Interfaces 11(45) (2019) 42549-42560.

45. Younis L.B., Viskanta R., 1993, Experimental Determination of the Volumetric Heat Transfer Coefficient Between Stream of Air and Ceramic Foam, International Journal of Heat and Mass Transfer 36(6) (1993) 1425-1434.

46. Hwang J.J., Hwang G.J., Yeh R.H., Chao C.H., Measurement of interstitial convective heat transfer and frictional drag for flow across metal foams, ASME Journal of Heat Transfer 124(1) (2002) 120-129.

47. Bhattacharya A., Calmidi V.V., Mahajan R.L., Thermophysical properties of high porosity metal foams, International Journal of Heat Mass Transfer 45(5) (2002) 1017-1031. 
48. Dukhan N., Correlations for the pressure drop for flow through metal foam, Experiments in Fluids 41(4) (2006) 665-672.

49. Wu Z., Caliot C., Bai F., Flamant G., Wang Z., Zhang J., Tian C., 2010, Experimental and numerical study on pressure drop in ceramic foams for volumetric solar receiver applications, Applied Energy 87(2) (2010) 504-513.

50. Verma P., Schiffer A., Kumar S., Thermoresistive and thermo-piezoresistive sensitivity of MWCNT/thermoplastic composites processed via additive manufacturing, Polymer Testing (In review), communicated in April (2020).

51. Incropera F.P., Dewitt D.P., Fundamentals of Heat and Mass Transfer, 5th edition, Wiley India, New Delhi, 2010.

52. Hesselgreaves J.E., Compact Heat Exchangers, first edition, Pergamon, Oxford, 2001.

53. Sui Y., Teo C.J., Lee P.S., Direct numerical simulation of fluid flow and heat transfer in periodic wavy channels with rectangular cross-sections, International Journal of Heat and Mass Transfer 55 (2012) 73-88.

54. Amani M., Ameri M., Kasaeian A., Investigating the convection heat transfer of Fe3O4 nanofluid in a porous metal foam tube under constant magnetic field, Experimental Thermal and Fluid Science 82 (2017) 439-449. 